\title{
Mexiletine Block of Voltage-Gated Sodium Channels: Isoform- and State-Dependent Drug-Pore Interactions
}

\author{
Hiroki Nakagawa, Tatsuo Munakata, and Akihiko Sunami \\ Department of Pharmaceutical Sciences, International University of Health and Welfare, Tochigi, Japan \\ Received August 18, 2018; accepted December 19, 2018
}

\begin{abstract}
Mexiletine is a class $\mathrm{lb}$ antiarrhythmic drug and is also used clinically to reduce or prevent myotonia. In addition, mexiletine has neuroprotective effects in models of brain ischemia. We compared state-dependent affinities of mexiletine for $\mathrm{Na}_{\mathrm{v}} 1.2$, $\mathrm{Na}_{v} 1.4$, and $\mathrm{Na}_{v} 1.5$ and examined the effects of mutations of transmembrane segment S6 residues on mexiletine block of $\mathrm{Na}_{\mathrm{v}}$ 1.5. Three channel isoforms had similar affinities of mexiletine for the rested state, and $\mathrm{Na}_{v} 1.4$ and $\mathrm{Na}_{\mathrm{v}} 1.5$ had similar affinities for the open and inactivated states, while $\mathrm{Na}_{\mathrm{v}} 1.2$ had lower affinity for these states than $\mathrm{Na}_{v} 1.4$ and $\mathrm{Na}_{\mathrm{v}} 1.5$. Mutational studies revealed that the largest affinity change was observed for an Ala substitution of Phe in domain IV S6. In our homology
\end{abstract}

modeling based on the bacterial $\mathrm{Na}^{+}$channel, mexiletine changed its location and orientation in the pore depending on the state of the channel, irrespective of the channel isoform. Mexiletine occurred in the upper part in the pore in the open state and lower in the closed state. High-affinity binding of mexiletine in the open states of $\mathrm{Na}_{\mathrm{v}} 1.4$ and $\mathrm{Na}_{\mathrm{v}} 1.5$ was caused by a $\pi-\pi$ interaction with Phe, whereas mexiletine was located away from $\mathrm{Phe}$ in the open state of $\mathrm{Na}_{\mathrm{v}} 1.2$. These results provide crucial information on the mechanism of isoform differences in state-dependent block by local anesthetics and related drugs. Mexiletine at upper locations in the open state may effectively cause an electrostatic mechanism of block.

\section{Introduction}

Mexiletine, a class Ib antiarrhythmic drug, is considered the first line for treating myotonic syndromes (Jackson et al., 1994; Hudson et al., 1995; Camerino et al., 2007). In addition, mexiletine is clinically useful to relieve neuropathic pain (Chabal et al., 1992) and protects brain neurons from injury in the models of ischemia (Stys and Lesiuk, 1996).

Mexiletine is an analog of the local anesthetic lidocaine and exerts its therapeutic action through blockade of voltage-gated $\mathrm{Na}^{+}$channels. Although mexiletine blocks various channel isoforms, there have been few reports on isoform differences in affinities of mexiletine. Affinity is known to vary as a function of the sodium channel gating state. It has been previously reported that the affinity of mexiletine for the inactivated channel is 2-fold higher in $\mathrm{Na}_{\mathrm{v}} 1.5$ than in $\mathrm{Na}_{\mathrm{v}} 1.2$ (Weiser et al., 1999) and $\mathrm{Na}_{\mathrm{v}} 1.5$ is more sensitive to use-dependent block by mexiletine than $\mathrm{Na}_{\mathrm{v}} 1.7$ (Wang et al., 2015). On the other hand, mexiletine caused more blocking for $\mathrm{Na}_{\mathrm{v}} 1.5$ than $\mathrm{Na}_{\mathrm{v}} 1.2$ or $\mathrm{Na}_{\mathrm{v}} 1.4$ by increasing the proportion of inactivated channels in $\mathrm{Na}_{\mathrm{v}} 1.5$ (Kawagoe et al., 2002). Although the isoform differences in local anesthetic affinity seem to be less than in toxin affinity (Fozzard and Hanck, 1996), understanding the molecular mechanisms of isoform differences in affinities may contribute to rational design of isoform-selective and safer $\mathrm{Na}^{+}$channel blockers.

This work was in part supported by the grant from International University of Health and Welfare (to A.S.).

https://doi.org/10.1124/mol.118.114025.
Elucidating the mechanisms of state-dependent block by local anesthetics is obviously important. Phe in domain IV S6 has long been known as a critical determinant of local anesthetic block (Ragsdale et al., 1994, 1996). Other residues in S6 segments of domains I, III, and IV also affect the local anesthetic binding (Wang et al., 1998, 2000; Nau et al., 1999; Yarov-Yarovoy et al., 2001, 2002). Although mutations of these residues are well known to have different effects on the block of the closed, open, and inactivated channels (Ragsdale et al., 1994, 1996; Wang et al., 1998, 2000; Nau et al., 1999; Yarov-Yarovoy et al., 2001, 2002), the molecular mechanisms of these differences have not been clarified. Several structural models of $\mathrm{Na}^{+}$channels have analyzed the interactions of local anesthetics with the pore residues in the closed (Tikhonov et al., 2006; Bruhova et al., 2008; Tikhonov and Zhorov, 2012) and open states (Lipkind and Fozzard, 2005; Tikhonov et al., 2006; Tikhonov and Zhorov, 2007, 2017). Lidocaine molecules adopted different locations and orientations in the closed and open states of the $\mathrm{Na}_{\mathrm{v}} 1.5$ model (Tikhonov et al., 2006), but most of their models are for either the closed or open state, and for either channel isoform of $\mathrm{Na}_{\mathrm{v}} 1.4$ or $\mathrm{Na}_{\mathrm{v}} 1.5$.

To our knowledge, there is no comparison of local anesthetics docking into two or more different channel isoforms. Previously, homology models were based on the bacterial $\mathrm{K}^{+}$ channel templates instead of the $\mathrm{Na}^{+}$channel templates (Lipkind and Fozzard, 2005; Tikhonov et al., 2006; Tikhonov and Zhorov, 2007; Bruhova et al., 2008). Nevertheless, sequences of mammalian $\mathrm{Na}^{+}$channels are more similar to the bacterial $\mathrm{Na}^{+}$channels than to the bacterial $\mathrm{K}^{+}$channels, and 
the $\mathrm{Na}^{+}$channel alignment is much less ambiguous than that of $\mathrm{K}^{+}$channels (Tikhonov and Zhorov, 2017). Actually, a novel distinct binding mode of lidocaine was found in the $\mathrm{Na}^{+}$channel model based on the $\mathrm{Na}^{+}$channel template (Tikhonov and Zhorov, 2017), but this mode was not revealed in the models based on the $\mathrm{K}^{+}$channel templates (Tikhonov et al., 2006; Tikhonov and Zhorov, 2007).

In the present study, we addressed isoform differences in state-dependent block of mexiletine. First, we measured statedependent affinities of mexiletine for $\mathrm{Na}_{\mathrm{v}} 1.2, \mathrm{Na}_{\mathrm{v}} 1.4$, and $\mathrm{Na}_{\mathrm{v}}$ 1.5. The affinities of mexiletine for the rested state were not different among these isoforms. $\mathrm{Na}_{\mathrm{v}} 1.4$ and $\mathrm{Na}_{\mathrm{v}} 1.5$ had similar affinities for the open and inactivated states, while $\mathrm{Na}_{\mathrm{v}} 1.2$ had a lower affinity for these states than $\mathrm{Na}_{\mathrm{v}} 1.4$ and $\mathrm{Na}_{\mathrm{v}}$ 1.5. We next visualized the interactions of mexiletine with the pore residues using bacterial $\mathrm{Na}^{+}$channel templates. Mexiletine was located at a different place in the closed and open states irrespective of the channel isoform, and mexiletine was found closer to the extracellular space in the open state. High-affinity binding of mexiletine in the open states of $\mathrm{Na}_{\mathrm{v}} 1.4$ and $\mathrm{Na}_{\mathrm{v}} 1.5$ was caused by a $\pi-\pi$ interaction with Phe, which was consistent with our mutational studies of $\mathrm{Na}_{\mathrm{v}} 1.5$. In contrast, mexiletine was not close to Phe in the open state of $\mathrm{Na}_{\mathrm{v}} 1.2$.

\section{Materials and Methods}

Site-Directed Mutagenesis and Transfection Procedure. The human heart $\mathrm{Na}^{+}$channel $\alpha$-subunit $\left(\mathrm{Na}_{\mathrm{v}} 1.5\right)$ clone in the pcDNA3. $1^{+}$plasmid (Invitrogen, Carlsbad, CA) was a generous gift from Dr. N. Makita (Nagasaki University). All mutations (N406A, L1462A, L1462F, L1462E, F1760A) of $\mathrm{Na}_{\mathrm{v}} 1.5$ were introduced using the QuikChange Site-Directed Mutagenesis Kit (Stratagene, La Jolla, $\mathrm{CA}$ ), according to the manufacturer's protocols and as described in our previous report (Sunami et al., 2004). Mutations were confirmed by DNA sequencing of the full-length plasmid. Human embryonic kidney cells (HEK293 cells) were transiently transfected with the plasmid encoding wild-type (WT) or mutant $\mathrm{Na}_{\mathrm{v}} 1.5$ channels using SuperFect (Qiagen, Hilden, Germany) in combination with a plasmid encoding CD8 (pIRES-CD8) to identify transfected cells with Dynabeads M-450 CD8 (Dynal, Oslo, Norway). Electrophysiologic measurements were performed 24-72 hours after transfection.

WT channels of the rat brain IIA $\left(\mathrm{Na}_{\mathrm{v}} 1.2\right)$ and the rat skeletal muscle $\mathrm{Na}^{+}$channel $\alpha$-subunit $\left(\mathrm{Na}_{\mathrm{v}} 1.4\right)$ were stably expressed in HEK293 cells. The pRc/CMV plasmid (Invitrogen) encoding $\mathrm{Na}_{\mathrm{v}} 1.2$ and the pCI-neo plasmid (Promega, Madison, WI) encoding $\mathrm{Na}_{\mathrm{v}} 1.4$ were generous gifts from Dr. H. A. Fozzard (University of Chicago). Selection of stablely transfected cells was made in Dulbecco's modified

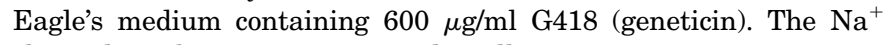
channel $\beta$-subunits were not used in all experiments.

Electrophysiology and Data Analyses. $\mathrm{Na}^{+}$currents were recorded with the whole-cell configuration of patch clamp using an Axopatch 200B amplifier (Axon Instruments, Union City, CA). Currents were filtered at $5 \mathrm{kHz}$ through a four-pole Bessel filter and digitized at $100 \mathrm{kHz}$ at 16-bit resolution with a Digidata 1322A acquisition system using pCLAMP 9 software (Axon Instruments). The pipettes had resistances between 1.0 and $1.5 \mathrm{M} \Omega$. Recordings were made at room temperature $\left(20-22^{\circ} \mathrm{C}\right)$ in a bathing solution containing (millimolar): $140 \mathrm{NaCl}, 2.5 \mathrm{KCl}, 2 \mathrm{CaCl}_{2}, 1 \mathrm{MgCl}_{2}$, 10 HEPES (pH 7.4 with $\mathrm{NaOH}$ ). The pipette solution was (millimolar): $100 \mathrm{CsF}, 40 \mathrm{NaCl}, 10 \mathrm{HEPES}$ (pH 7.2 with $\mathrm{CsOH}$ ).

To determine the activation parameters, the current-voltage (I-V) relationship was fitted to a transform of a Boltzmann distribution: $I=$ $\left(V-V_{\text {rev }}\right) G_{\max } /\left\{1+\exp \left[\left(V_{1 / 2}-V\right) / s\right]\right\}$, where $I$ is the peak $\mathrm{Na}^{+}$current during the test pulse of voltage $V$. The parameters estimated by the fitting were $V_{1 / 2}$ (the voltage for half-activation), $s$ (slope factor), $V_{\text {rev }}$ (the reversal potential), and $G_{\max }$ (the maximum peak conductance). After induction of steady-state inactivation by 1-second depolarizing prepulses from a holding potential of $-130 \mathrm{mV}$, the $\mathrm{Na}^{+}$currents were measured during test pulses to -20 or $0 \mathrm{mV}$ applied every 4 seconds. Availability was described by the following Boltzmann equation: $I / I_{\max }=$ $1 /\left\{1+\exp \left[\left(V-V_{1 / 2}\right) / s\right]\right\}$, where $I$ is the peak current, $I_{\max }$ is the maximum peak current, $V$ is the prepulse voltage, $V_{1 / 2}$ is the voltage for halfinactivation, and $s$ is the slope factor. The recovery from inactivation induced by 10 -millisecond depolarization to $-10 \mathrm{mV}$ was monitored, and the time course of recovery was fitted by a single exponential. The time to decay from $90 \%$ to $10 \%$ of the peak current at $0 \mathrm{mV}$ was also measured.

For mexiletine block experiments, a train of 30 pulses of 5- or 200-millisecond duration was applied at 300-millisecond interpulse intervals in the absence or presence of mexiletine. To compare the sensitivity of three channel isoforms to mexiletine block, we used holding potentials of $-120 \mathrm{mV}$ for $\mathrm{Na}_{\mathrm{v}} 1.2$ and $\mathrm{Na}_{\mathrm{v}} 1.4$, and $-130 \mathrm{mV}$ for $\mathrm{Na}_{\mathrm{v}} 1.5$, and test potentials of $0 \mathrm{mV}$ for $\mathrm{Na}_{\mathrm{v}} 1.2$ and $\mathrm{Na}_{\mathrm{v}} 1.4$, and $-20 \mathrm{mV}$ for $\mathrm{Na}_{\mathrm{v}} 1.5$. These voltages were chosen based on the gating data (Table 1), and the voltages minimized the gating effects on mexiletine block. In $\mathrm{Na}_{\mathrm{v}} 1.5$ mutant channels, tonic (or rested) and use-dependent block by mexiletine were produced by a train of 30 pulses of 5- or 200-millisecond duration applied to 0 (N406A, L1462E), -5 (L1462A), or $-20 \mathrm{mV}$ (L1462F, F1760A) from a holding potential of -130 (N406A, L1462A, F1760A) or $-140 \mathrm{mV}$ (L1462E, L1462F). The dissociation constants of mexiletine for the rested $\left(\mathrm{K}_{\mathrm{R}}\right)$, open $\left(\mathrm{K}_{\mathrm{O}}\right)$, and inactivated $\left(\mathrm{K}_{\mathrm{I}}\right)$ states of the channels were determined by the concentration-response curves for tonic block, and for total block (tonic block + use-dependent block) caused by 5 - and 200-millisecond depolarizing pulses, respectively. Mexiletine was obtained from Sigma-Aldrich (St. Louis, MO).

Data were analyzed using pCLAMP 9 (Axon Instruments) and SigmaPlot (SPSS, Chicago, IL). Pooled data are presented as the mean \pm S.D. Statistical comparisons were made by using one- or two-way analysis of variance.

Molecular Modeling and Docking. As with our previous study (Sunami et al., 2004), we built homology models of the closed and open pores of $\mathrm{Na}_{\mathrm{v}} 1.2, \mathrm{Na}_{\mathrm{v}} 1.4$, and $\mathrm{Na}_{\mathrm{v}} 1.5$ based on the crystal structures of bacterial voltage-gated $\mathrm{Na}^{+}$channels, $\mathrm{Na}_{\mathrm{v}} \mathrm{Ab}$ (for closed channel; PDB accession code 3RVY; Payandeh et al., 2011) and $\mathrm{Na}_{\mathrm{v}} \mathrm{Ms}$ (for open channel; PDB accession code 5HVX; Sula et al., 2017) using MODELER version 9.17 (Šali and Blundell, 1993). Sequence alignments of the pore regions of $\mathrm{Na}_{\mathrm{v}} \mathrm{Ab}, \mathrm{Na}_{\mathrm{v}} \mathrm{Ms}, \mathrm{Na}_{\mathrm{v}} 1.2, \mathrm{Na}_{\mathrm{v}} 1.4$, and $\mathrm{Na}_{\mathrm{v}} 1.5$ are given in Fig. 1. The geometry optimization and partial charge calculation of mexiletine was performed using the PM6 method of MOPAC2009 (http://OpenMOPAC.net). Docking mexiletine in these models was performed using the lamarckian genetic algorithm of AutoDock4.2.6 and AutoDockTools (Morris et al., 2009). Side-chain flexibility was allowed during docking for the following $\$ 6$ residues: S401, V405, I408, N927, L931, F934, S1458, T1461, L1462, F1465, $\mathrm{F} 1760$, V1764, and $\mathrm{Y} 1767$ in $\mathrm{Na}_{\mathrm{v}} 1.5$, and the equivalent residues in $\mathrm{Na}_{\mathrm{v}} 1.2$ and $\mathrm{Na}_{\mathrm{v}} 1.4$. The docking grid was composed of $28 \times 28 \times$ 31 points with a point spacing of $1 \AA$. Autodock was run using the default parameter set except for "Number of GA Runs" set to 350. The docking results were visualized using Biovia Discovery Studio Visualizer (Dassault Systemes Biovia, 2016).

\section{Results}

Isoform Differences in Mexiletine Block. We first compared the sensitivity of $\mathrm{Na}_{\mathrm{v}} 1.2, \mathrm{Na}_{\mathrm{v}} 1.4$, and $\mathrm{Na}_{\mathrm{v}} 1.5$ to tonic block (first-pulse block or rested block) by mexiletine, which was measured at the holding potential of $-120 \mathrm{mV}$ for $\mathrm{Na}_{\mathrm{v}} 1.2$ and $\mathrm{Na}_{\mathrm{v}} 1.4$, and $-130 \mathrm{mV}$ for $\mathrm{Na}_{\mathrm{v}} 1.5$. In $\mathrm{Na}_{\mathrm{v}} 1.5$, tonic block by $40 \mu \mathrm{M}$ mexiletine was $9.5 \% \pm 5.8 \%(n=5)$ and was not significantly different from the tonic block of $\mathrm{Na}_{\mathrm{v}} 1.2$ $(4.5 \% \pm 9.6 \%, n=5)$ or $\mathrm{Na}_{\mathrm{v}} 1.4(8.0 \% \pm 2.5 \%, n=5)($ Fig. $2, \mathrm{~A}$ and $\mathrm{B})$. 
TABLE 1

Gating parameters of $\mathrm{Na}_{\mathrm{v}} 1.2, \mathrm{Na}_{\mathrm{v}} 1.4, \mathrm{Na}_{\mathrm{v}} 1.5$, and $\mathrm{Na}_{\mathrm{v}} 1.5$ mutants

The voltage dependence of activation and inactivation, and recovery from fast inactivation were measured by the method described in Materials and Methods. Data represent the mean \pm S.D.

\begin{tabular}{|c|c|c|c|c|c|c|c|c|c|c|}
\hline & \multicolumn{3}{|c|}{ Activation } & \multicolumn{3}{|c|}{ Inactivation } & \multicolumn{2}{|c|}{$I_{\mathrm{Na}}$ Decay $($ at $0 \mathrm{mV}$ ) } & \multicolumn{2}{|l|}{ Recovery } \\
\hline & $V_{1 / 2}$ & $s$ & $n$ & $V_{1 / 2}$ & $s$ & $n$ & Decay time & $n$ & $\tau$ & $n$ \\
\hline & \multicolumn{2}{|c|}{$m V$} & \multicolumn{3}{|c|}{$m V$} & \multicolumn{3}{|c|}{$m s$} & \multicolumn{2}{|l|}{$m s$} \\
\hline $\mathrm{Na}_{\mathrm{v}} 1.2$ & $-19.4 \pm 3.4$ & $5.6 \pm 0.6$ & 8 & $-54.1 \pm 3.4$ & $5.1 \pm 0.8$ & 8 & $1.3 \pm 0.3$ & 8 & $1.0 \pm 0.3$ & 7 \\
\hline $\mathrm{Na}_{\mathrm{v}} 1.4$ & $-22.4 \pm 2.5$ & $6.4 \pm 0.7$ & 5 & $-60.3 \pm 5.1$ & $6.7 \pm 0.7$ & 6 & $1.0 \pm 0.1$ & 5 & $0.8 \pm 0.2$ & 5 \\
\hline $\mathrm{Na}_{\mathrm{v}} 1.5$ & $-51.3 \pm 5.8$ & $5.6 \pm 0.4$ & 5 & $-90.3 \pm 6.5$ & $4.9 \pm 0.6$ & 8 & $1.8 \pm 1.1$ & 5 & $5.5 \pm 0.7$ & 6 \\
\hline \multicolumn{11}{|c|}{$\mathrm{Na}_{\mathrm{v}} 1.5$ mutants } \\
\hline N406A & $-34.0 \pm 6.9$ & $8.1 \pm 1.7$ & 6 & $-89.0 \pm 3.7$ & $5.0 \pm 0.6$ & 8 & $0.9 \pm 0.2$ & 6 & $1.4 \pm 0.3$ & 8 \\
\hline L1462A & $-38.0 \pm 2.7$ & $6.4 \pm 1.0$ & 6 & $-92.4 \pm 2.4$ & $4.8 \pm 0.7$ & 6 & $0.7 \pm 0.1$ & 6 & $8.9 \pm 1.2$ & 6 \\
\hline L1462E & $-31.8 \pm 6.8$ & $6.9 \pm 0.8$ & 4 & $-98.2 \pm 4.9$ & $5.7 \pm 0.9$ & 5 & $0.8 \pm 0.2$ & 4 & $11.6 \pm 3.4$ & 4 \\
\hline $\mathrm{L} 1462 \mathrm{~F}$ & $-44.4 \pm 4.9$ & $6.0 \pm 0.4$ & 5 & $-101.0 \pm 6.9$ & $4.5 \pm 0.7$ & 12 & $0.5 \pm 0.2$ & 5 & $11.3 \pm 4.5$ & 7 \\
\hline F1760A & $-52.3 \pm 5.9$ & $5.8 \pm 0.7$ & 6 & $-81.9 \pm 6.0$ & $4.8 \pm 0.3$ & 9 & $2.0 \pm 1.0$ & 6 & $4.4 \pm 0.7$ & 6 \\
\hline
\end{tabular}

Decay time, time to decay from $90 \%$ to $10 \%$ of the peak current at $0 \mathrm{mV} ; n$, number of cells; $s$, slope factor; $\tau$, time constant; $V_{1 / 2}$, voltage for halfactivation or half-inactivation.

We next compared use-dependent block by mexiletine in three channel isoforms. In the control, a train of 30 pulses of 5or 200-millisecond pulse duration produced no discernible block in three isoforms. After application of $40 \mu \mathrm{M}$ mexiletine, the three isoforms exhibited use-dependent block with 5 -millisecond pulses $\left(\mathrm{Na}_{\mathrm{v}} 1.2,8.1 \% \pm 1.3 \%, n=5 ; \mathrm{Na}_{\mathrm{v}} 1.4\right.$, $13.5 \% \pm 2.7 \%, n=5 ; \mathrm{Na}_{\mathrm{v}} 1.5,15.2 \% \pm 4.5 \%, n=5$ ), and usedependent block became bigger with 200 -millisecond pulses in all isoforms $\left(\mathrm{Na}_{\mathrm{v}} 1.2,20.2 \% \pm 2.2 \%, n=5 ; \mathrm{Na}_{\mathrm{v}} 1.4,37.2 \% \pm\right.$ $\left.2.2 \%, n=5 ; \mathrm{Na}_{\mathrm{v}} 1.5,38.9 \% \pm 5.4 \%, n=5\right)$. The amount of activated and inactivated channel block by mexiletine was consistent with the previous reports (Ono et al., 1994; Carmeliet and Mubagwa, 1998; Sasaki et al., 2004). When we compared the amounts of use-dependent block with 5- or 200-millisecond pulses among these three isoforms, $\mathrm{Na}_{\mathrm{v}} 1.4$ and $\mathrm{Na}_{\mathrm{v}} 1.5$ showed similar sensitivity to use-dependent block, and $\mathrm{Na}_{\mathrm{v}} 1.2$ showed significantly less sensitivity than $\mathrm{Na}_{\mathrm{v}} 1.4$ or $\mathrm{Na}_{\mathrm{v}} 1.5(P<0.05$ or $P<0.001)$ (Fig. $\left.2 \mathrm{C}\right)$.

When we compared the dissociation constants of mexiletine for three states of $\mathrm{Na}_{\mathrm{v}} 1.2, \mathrm{Na}_{\mathrm{v}} 1.4$, and $\mathrm{Na}_{\mathrm{v}} 1.5$, the $\mathrm{K}_{\mathrm{R}}$ values
P1-helix

NavAb

NavMs

Nav1.2 I

Nav1.2 II

Nav1.2 III

Nav1.2 IV

Nav1. 4 I

Nav1.4 II

Nav1.4 III

Nav1. 4 IV

Nav1.5 I

Nav1.5 II

Nav1. 5 III

Nav1.5 IV
GESFYTLFQVM SKSTYTI,

$\begin{array}{ll}\text { SWAFLSLFRLM } & \text { TQDFW } \\ \text { FHSFLIVFRVL } & \text { CGE-W } \\ \text { GLGYLSLLQVA } & \text { TFKGW } \\ \text { GNSMICLFQIT } & \text { TSAGW }\end{array}$

SWAFLALFRLM

FHSFLIVFRIL GLGYLSLLQVA GNSIICLFEIT

TQDYW CGE-W TFKGW TSAGW

AWAFLALFRLM TQDCW FHAFLIIFRIL CGE-W GAGYLALLQVA TFKGW ANSMLCLFQIT TSAGW
P2-helix

SMGIVRPLMEV YP SMGIVRPVMNV HP

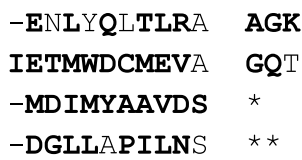

-ENLFOLTLRA IETMWDCMEVA -MDIMYAAVDS -DGLLNPILNS

-ERLYQQTLRS IETMWDCMEVS -MDIMYAAVDS -DGLLSPILNT inner helix (S6)

YAWVFFIPFIFVVTFVMINLVVAIIVDAM 221 NAWVFFIPFIMLTTFTVLNLFIGIIVDAM 222

TYMIFFVLVIFLGSFYLINLILAVVAMAY 428 MCLTVFMMVMVIGNLVVLNLFLALLLSSF 986 YMYLYFVIFIIFGSFFTLNLFIGVIIDNF 1476 VGIFFFVSYIIISFLVVVNMYIAVILENF 1779

TYMIFFVVIIFLGSFYLINLILAVVAMAY 444 MCLTVFLMVMVIGNLVVLNLFLALLLSSF 799 YMYLYFVIFIIFGSFFTLNLFIGVIIDNF 1291 IGICFFCSYIIISFLIVVNMYIAIILENF 1594

IYMIFFMLVIFLGSFYLVNLILAVVAMAY 416 LCLLVFLLVMVIGNLVVLNLFLALLLSSF 942 YMYIYFVIFIIFGSFFTLNLFIGVIIDNF 1473 VGILFFTTYIIISFLIVVNMYIAIILENF 1775

\footnotetext{
* : RNVELQPKYEDNL

* * : GPPDCDPDKDHPGSSVKRDCGNPS

\# : REKEEQPHYEVNL

\#\#: GPPDCDPTLENPGTNVRGDCGNPS

$+:$ RGYEEQPQWEYNL

++ : GPPYCDPTLPNSNGS-RGDCGSPA
}

Fig. 1. Sequence alignment of the pore regions of $\mathrm{Na}_{\mathrm{v}} \mathrm{Ab}, \mathrm{Na}_{\mathrm{v}} \mathrm{Ms}, \mathrm{Na}_{\mathrm{v}} 1.2, \mathrm{Na}_{\mathrm{v}} 1.4$, and $\mathrm{Na}_{\mathrm{v}} 1.5$. The proposed identities of the P1 and $\mathrm{P} 2 \mathrm{helices}$, and the inner helix or the transmembrane segment $\mathrm{S} 6$ are indicated above the sequences. The number next to each inner helix or S6 sequence indicates the amino acid number of the end of each inner helix or $\mathrm{S} 6$. The amino acid residues indicated in bold are conserved among $\mathrm{Na}_{\mathrm{v}} 1.2, \mathrm{Na}_{\mathrm{v}} 1.4, \mathrm{and} \mathrm{Na}_{\mathrm{v}} 1.5$. The residues in red (N406, L1462, F1760) were mutated in the present study, and these are conserved among these three channels. 
A

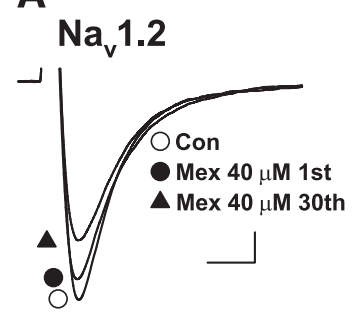

B

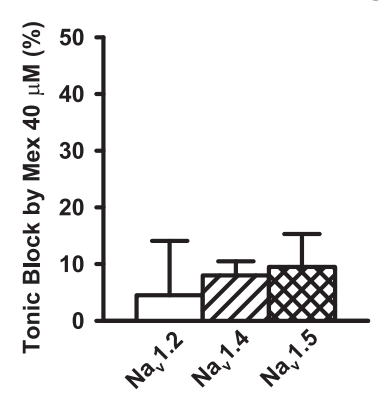

$\mathrm{Na}_{\mathrm{v}} 1.4$

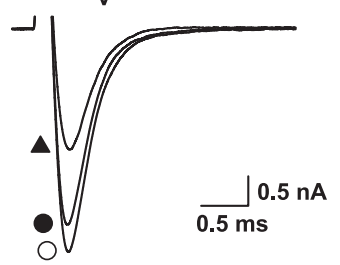

$\mathrm{C}$

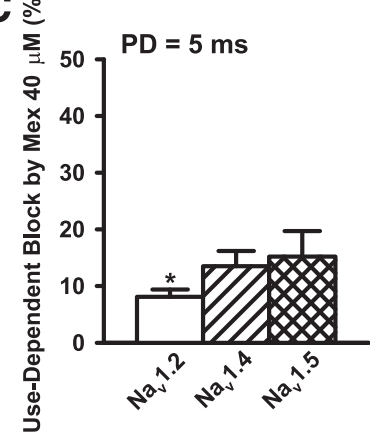

$\mathrm{Na}_{\mathrm{v}} 1.5$
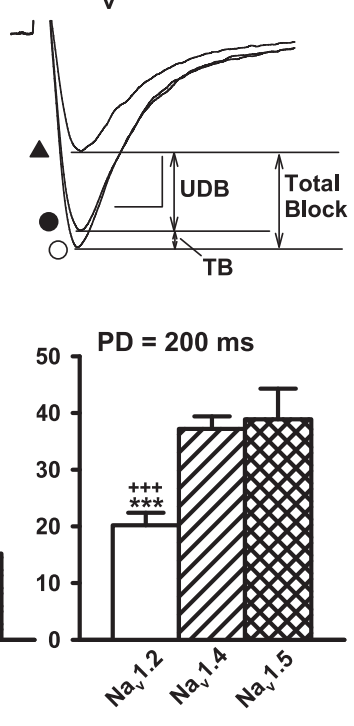

Fig. 2. Tonic and use-dependent block by mexiletine of $\mathrm{Na}_{\mathrm{v}} 1.2, \mathrm{Na}_{\mathrm{v}} 1.4$, and $\mathrm{Na}_{\mathrm{v}} 1.5$. (A) Typical current traces before (Con) and after application of $40 \mu \mathrm{M}$ mexiletine (Mex) recorded from $\mathrm{Na}_{\mathrm{v}} 1.2$ (left), $\mathrm{Na}_{\mathrm{v}} 1.4$ (middle), and $\mathrm{Na}_{\mathrm{v}} 1.5$ (right). To produce tonic block (TB) and usedependent block (UDB) by mexiletine, a train of 30 pulses of 200-millisecond duration was applied at 300-millisecond interpulse intervals in the absence and presence of mexiletine. Current traces are during the first pulse for the control, and the 1st and 30th pulses for mexiletine. See Materials and Methods for the voltages of the pulse protocol. (B) Tonic block of $\mathrm{Na}_{\mathrm{v}} 1.2, \mathrm{Na}_{\mathrm{v}} 1.4$, and $\mathrm{Na}_{\mathrm{v}} 1.5$ by $40 \mu \mathrm{M}$ mexiletine. (C) Use-dependent block of $\mathrm{Na}_{\mathrm{v}} 1.2, \mathrm{Na}_{\mathrm{v}} 1.4$, and $\mathrm{Na}_{\mathrm{v}} 1.5$ by $40 \mu \mathrm{M}$ mexiletine. Use-dependent block by mexiletine was produced by 30 pulses with (left) 5 - or (right) 200-millisecond pulse duration (PD) at 300-millisecond interpulse intervals. In $B$ and $C$, data represent the mean \pm S.D. from five cells. $* P<0.05$; $* * * P<0.001$ compared with $\mathrm{Na}_{\mathrm{v}} 1.5 ;{ }^{+++} P<0.001$ compared with $\mathrm{Na}_{\mathrm{v}} 1.4$, two-way analysis of variance followed by Bonferroni test. were not much different among these three isoforms $\left(\mathrm{Na}_{\mathrm{v}} 1.2\right.$, $\mathrm{K}_{\mathrm{R}}=323.2 \pm 126.7 \mu \mathrm{M}, n=8 ; \mathrm{Na}_{\mathrm{v}} 1.4, \mathrm{~K}_{\mathrm{R}}=315.1 \pm 87.1 \mu \mathrm{M}$, $n=8 ; \mathrm{Na}_{\mathrm{v}} 1.5, \mathrm{~K}_{\mathrm{R}}=270.3 \pm 70.1 \mu \mathrm{M}, n=6$ ) (Fig. 3 ). On the other hand, $\mathrm{Na}_{\mathrm{v}} 1.4$ and $\mathrm{Na}_{\mathrm{v}} 1.5$ showed similar affinities for the open and inactivated states, and they had a 2- to 3-fold higher affinity for these states than $\mathrm{Na}_{\mathrm{v}} 1.2\left(\mathrm{Na}_{\mathrm{v}} 1.2, \mathrm{~K}_{\mathrm{O}}=\right.$ $190.5 \pm 71.3 \mu \mathrm{M}, n=8, \mathrm{~K}_{\mathrm{I}}=163.6 \pm 52.6 \mu \mathrm{M}, n=13 ; \mathrm{Na}_{\mathrm{v}} 1.4$, $\mathrm{K}_{\mathrm{O}}=95.2 \pm 36.4 \mu \mathrm{M}, n=5, \mathrm{~K}_{\mathrm{I}}=50.9 \pm 4.5 \mu \mathrm{M}, n=5 ; \mathrm{Na}_{\mathrm{v}} 1.5$, $\left.\mathrm{K}_{\mathrm{O}}=92.4 \pm 25.9 \mu \mathrm{M}, n=5, \mathrm{~K}_{\mathrm{I}}=48.3 \pm 14.9 \mu \mathrm{M}, n=6\right)$. In the three channel isoforms, the open state affinity was 1.7- to 3.3fold higher and the inactivated state affinity was 2.0- to 6.2fold higher than the rested state.

Mutational Effects of S6 on Mexiletine Block. Because mutations of S6 residues, Asn in domain I (N418 in $\mathrm{Na}_{\mathrm{v}} 1.2, \mathrm{~N} 434$ in $\mathrm{Na}_{\mathrm{v}} 1.4$ ), Leu in domain III (L1465 in $\mathrm{Na}_{\mathrm{v}} 1.2$, L1280 in $\mathrm{Na}_{\mathrm{v}} 1.4$ ), and Phe in domain IV (F1764 in $\mathrm{Na}_{\mathrm{v}} 1.2$, F1579 in $\mathrm{Na}_{\mathrm{v}} 1.4$ ) affected local anesthetic binding (Ragsdale et al., 1994, 1996; Wang et al., 1998, 2000; Nau et al., 1999; Yarov-Yarovoy et al., 2001, 2002) and because most of these observations were from $\mathrm{Na}_{\mathrm{v}} 1.2$ and $\mathrm{Na}_{\mathrm{v}} 1.4$, we examined the effects of mutations of these equivalent residues (N406, L1462, F1760) on mexiletine block in $\mathrm{Na}_{\mathrm{v}}$ 1.5. Substitution of Asn-406 with Ala (N406A) significantly increased tonic block $(26.7 \% \pm 3.7 \%, n=7, P<0.001)$ and decreased use-dependent block by $40 \mu \mathrm{M}$ mexiletine $(12.5 \% \pm 3.7 \%, n=7, P<0.001)$ compared with WT (tonic block, $9.5 \% \pm 5.8 \%, n=5$; usedependent block, $38.9 \% \pm 5.4 \%, n=5$ ) (Fig. 4). Replacement of Phe-1760 with Ala $(\mathrm{F} 1760 \mathrm{~A})$ reduced tonic block $(0.0 \% \pm 4.5 \%$, $n=5)$ and significantly decreased use-dependent block $(3.2 \% \pm 1.1 \%, n=5, P<0.001$ vs. WT). Substitution of Leu1462 with a negatively charged residue, Glu (L1462E) significantly decreased use-dependent block $(11.4 \% \pm 4.0 \%, n=7$, $P<0.001$ vs. WT), and the Phe mutant of Leu-1462 (L1462F) significantly increased use-dependent block $(49.1 \% \pm 5.6 \%$, $n=7, P<0.01$ vs. WT).

In Fig. 5, the mutational effects of N406, L1462, and F1760 on the dissociation constants of mexiletine for three states are summarized. The largest affinity changes were observed in F1760A. F1760A decreased the affinity of mexiletine for the inactivated state 9 -fold $\left(\mathrm{K}_{\mathrm{I}}=429.5 \pm 147.9 \mu \mathrm{M}, n=6\right)$. This was consistent with the previous reports showing that an important part of the local anesthetic binding site includes F1764 in $\mathrm{Na}_{\mathrm{v}} 1.2$ (equivalent to $\mathrm{F} 1760$ in $\mathrm{Na}_{\mathrm{v}}$ 1.5) (Ragsdale et al., 1994, 1996). In addition, F1760A decreased affinities for the rested and open states by 2 -fold and 5-fold, respectively $\left(\mathrm{K}_{\mathrm{R}}=515.3 \pm 183.6 \mu \mathrm{M}, n=5 ; \mathrm{K}_{\mathrm{O}}=480.5 \pm 138.4 \mu \mathrm{M}, n=6\right)$.

Changes in affinities for the open and inactivated states were also observed in L1462 mutations. L1462E decreased affinity for the open state 1.5 -fold $\left(\mathrm{K}_{\mathrm{O}}=138.6 \pm 22.8 \mu \mathrm{M}, n=5\right)$ and inactivated state 2.3 -fold $\left(\mathrm{K}_{\mathrm{I}}=113.1 \pm 25.0 \mu \mathrm{M}, n=5\right)$.

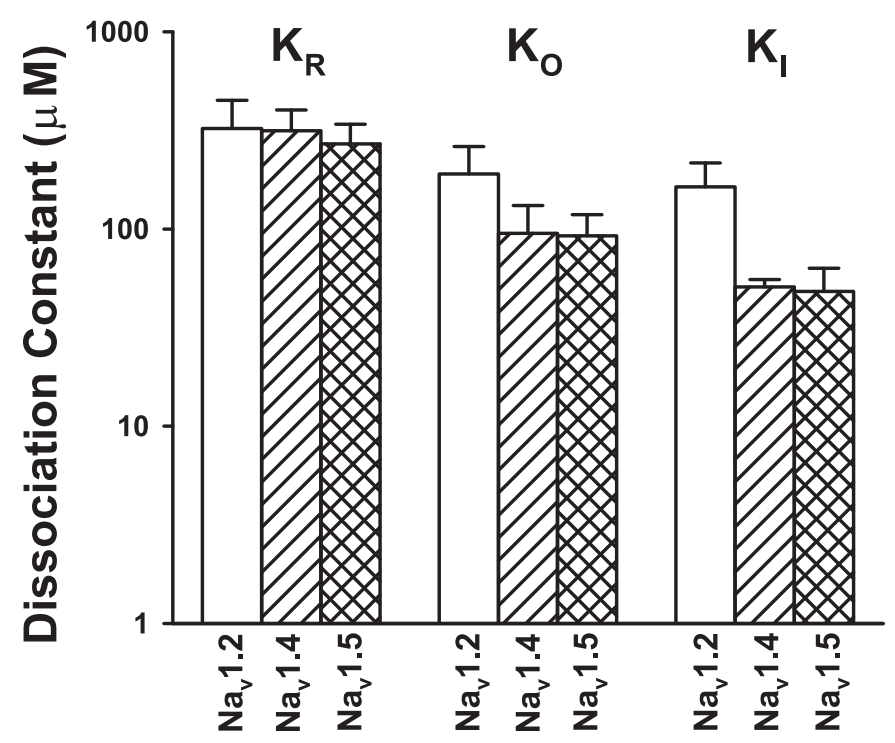

Fig. 3. Dissociation constants of mexiletine for three states of $\mathrm{Na}_{\mathrm{v}} 1.2$, $\mathrm{Na}_{\mathrm{v}}$ 1.4, and $\mathrm{Na}_{\mathrm{v}}$ 1.5. The dissociation constants of mexiletine for the rested $\left(\mathrm{K}_{\mathrm{R}}\right)$, open $\left(\mathrm{K}_{\mathrm{O}}\right)$, and inactivated $\left(\mathrm{K}_{\mathrm{I}}\right)$ states were determined by the concentration-response curves for tonic block and for total block (tonic block + use-dependent block) caused by 5 - and 200-millisecond depolarizing pulses, respectively. Data represent the mean \pm S.D. from five to eight cells except $\mathrm{Na}_{\mathrm{v}} 1.2 \mathrm{~K}_{\mathrm{I}}(13$ cells). See Materials and Methods and the inset shown in Fig. 2A for more details of definition of block and dissociation constants. 
A

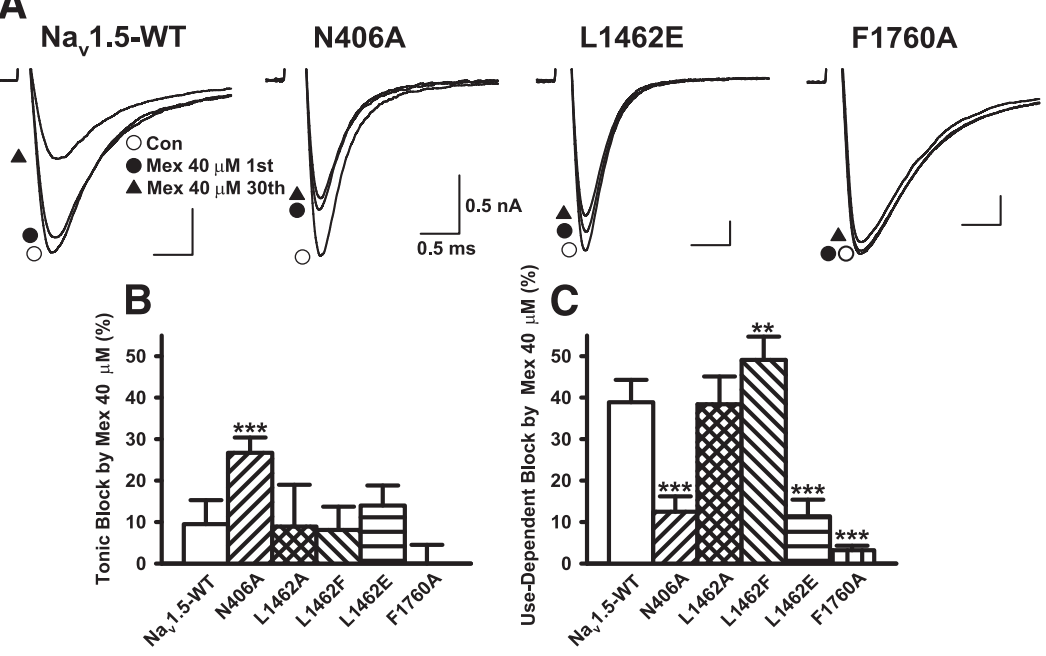

Fig. 4. Effects of $\mathrm{Na}_{\mathrm{v}} 1.5$ mutants on mexiletine block. (A) Typical current traces before (Con) and after application of $40 \mu \mathrm{M}$ mexiletine (Mex) recorded from $\mathrm{Na}_{\mathrm{v}} 1.5 \mathrm{WT}, \mathrm{N} 406 \mathrm{~A}$, L1462E, and F1760A. Current traces in each panel are during the first pulse in a train of 30 pulses for the control, and the 1st and 30th pulses for mexiletine. (B) Summary of tonic block of WT, and mutants of N406, L1462, and F1760 by $40 \mu \mathrm{M}$ mexiletine. (C) Summary of use-dependent block of WT, and mutants of N406, L1462, and F1760 by $40 \mu \mathrm{M}$ mexiletine. In $A$ through $C$, the tonic and use-dependent blocks were produced by a train of 30 pulses with 200 millisecond duration applied at 300-millisecond interpulse intervals in the absence or presence of mexiletine. See Materials and Methods for the voltages of the pulse protocol. In $B$ and $C$, data represent the mean \pm S.D. from five to seven cells. $* * * P<0.001 ; * * P<0.01$ compared with WT, one-way analysis of variance followed by Dunnett's test.

L1462F increased affinities for the open and inactivated states by 1.8-fold and 2.3-fold, respectively $\left(\mathrm{K}_{\mathrm{O}}=51.3 \pm 13.0 \mu \mathrm{M}\right.$, $\left.n=7 ; \mathrm{K}_{\mathrm{I}}=21.3 \pm 9.3 \mu \mathrm{M}, n=7\right)$, but $\mathrm{L} 1462 \mathrm{~F}$ had no effect on affinity for the rested state $\left(\mathrm{K}_{\mathrm{R}}=270.8 \pm 77.4 \mu \mathrm{M}, n=6\right)$. By contrast, N406A increased affinity for the rested state by 2.7fold $\left(\mathrm{K}_{\mathrm{R}}=101.3 \pm 9.6 \mu \mathrm{M}, n=5\right)$ and decreased affinity for the inactivated state by 1.7 -fold $\left(\mathrm{K}_{\mathrm{I}}=80.4 \pm 9.4 \mu \mathrm{M}, n=5\right)$.

The Pore Models of Closed and Open $\mathrm{Na}_{\mathrm{v}} 1.5$ Channel. We built homology models of the inner pore of the closed and open $\mathrm{Na}_{\mathrm{v}} 1.5$ channel based on the crystal structures of bacterial voltage-gated $\mathrm{Na}^{+}$channels, $\mathrm{Na}_{\mathrm{v}} \mathrm{Ab}$ (for closed channel) (Payandeh et al., 2011) and $\mathrm{Na}_{\mathrm{v}} \mathrm{Ms}$ (for open channel) (Sula et al., 2017). Because the transmembrane pore regions of $\mathrm{Na}_{\mathrm{v}} \mathrm{Ab}$ and $\mathrm{Na}_{\mathrm{v}} \mathrm{Ms}$ have high sequence identities (McCusker et al., 2012), structure differences seen in the models are likely to be state dependent rather than a consequence of sequence dissimilarities (Bagnéris et al., 2015). Our pore model was composed of $\mathrm{P} 1$ and $\mathrm{P} 2$ helices, nonhelix linkers including the selectivity filter residues between the P1 and P2 helices, and the $\mathrm{S} 6$ segments (Fig. 6). In our pore model of $\mathrm{Na}_{\mathrm{v}} 1.5, \mathrm{~F} 1760$ in domain IV S6 and L1462 in domain III S6 faced the inner pore in both the closed and open states of the channel, which was consistent with the previous experimental evidence using a cysteine mutant of F1579 in $\mathrm{Na}_{\mathrm{v}} 1.4$ (equivalent to F1760 in $\mathrm{Na}_{\mathrm{v}}$ 1.5) and the charged methanethiosulfonate reagents (Sunami et al., 2004), and many studies of local anesthetic block (Ragsdale et al., 1994, 1996; Wang et al., 2000; YarovYarovoy et al., 2001; Nau et al., 2003). On the other hand, N406 in domain I S6 did not face the inner pore irrespective of the channel states.

Docking Simulations of Mexiletine in the Inner Pore of $\mathbf{N a}_{\mathbf{v}}$ 1.5. We docked mexiletine in our inner pore model of the closed and open $\mathrm{Na}_{\mathrm{v}} 1.5$ channels. The lowest energy poses of mexiletine docked inside the inner pore are shown in the closed and open channels (Fig. 7). In the closed channel, mexiletine was in the middle part of the inner pore, and the drug was not close to L1462 and F1760 (Fig. 7A). In the open channel, mexiletine moved closer to the extracellular space in the inner pore and was nearer to L1462 and F1760 compared with the closed channel (Fig. 7B). In particular, mexiletine interacted with F1760 through a $\pi-\pi$ interaction with a distance of $3.65 \AA$ between the aromatic ring centers of the drug and F1760. These docking results were consistent with those of the present mutational studies showing that F1760 was more involved in mexiletine binding in the open and inactivated channels than in the rested channel.

Docking Simulations of Mexiletine in the Inner Pore of $\mathrm{Na}_{\mathbf{v}} \mathbf{1 . 2}$ and $\mathrm{Na}_{\mathbf{v}}$ 1.4. In the open and inactivated channels, $\mathrm{Na}_{\mathrm{v}} 1.4$ had similar affinity for mexiletine compared with $\mathrm{Na}_{\mathrm{v}} 1.5$, and $\mathrm{Na}_{\mathrm{v}} 1.2$ had lower affinity than $\mathrm{Na}_{\mathrm{v}} 1.4$ and $\mathrm{Na}_{\mathrm{v}}$ 1.5. In the rested channels, affinities for mexiletine were not different among these isoforms. To compare the relative location of mexiletine in these isoforms, we built the models of the inner pore of $\mathrm{Na}_{\mathrm{v}} 1.2$ and $\mathrm{Na}_{\mathrm{v}} 1.4$ in a similar manner to that of $\mathrm{Na}_{\mathrm{v}} 1.5$, and then docked mexiletine inside the pore of the closed and open channels.

In the closed $\mathrm{Na}_{\mathrm{v}} 1.2$ channel, mexiletine was located relatively close to L1465 and away from F1764 (Fig. 8A). In the open $\mathrm{Na}_{\mathrm{v}} 1.2$ channel, mexiletine moved toward the extracellular space in the pore but remained away from F1764 (Fig. 8B). On the other hand, mexiletine in $\mathrm{Na}_{\mathrm{v}} 1.4$ behaved

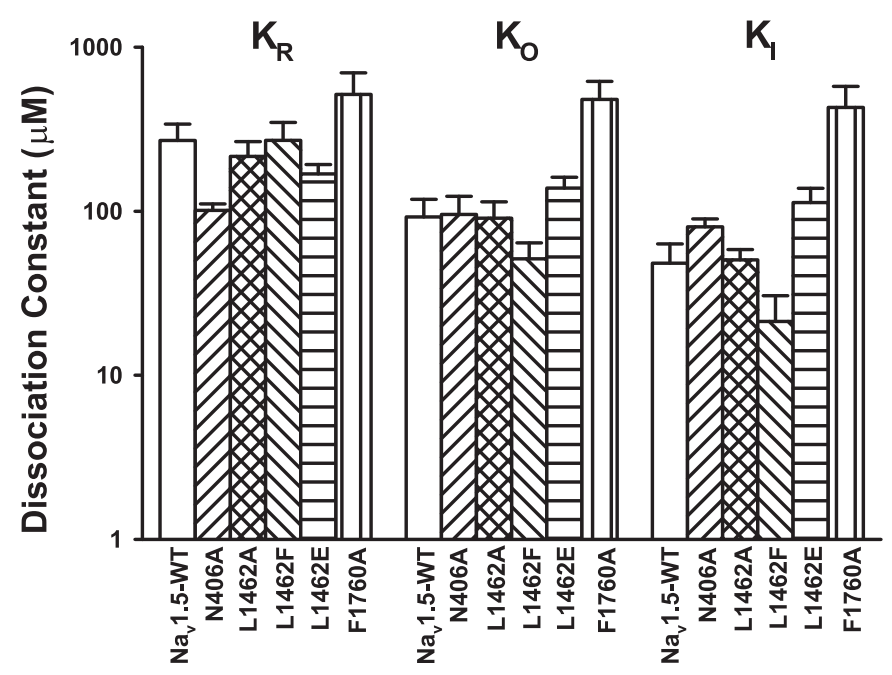

Fig. 5. Effects of $\mathrm{Na}_{\mathrm{v}} 1.5$ mutants on dissociation constants of mexiletine for three states. Data represent the mean \pm S.D. from five to eight cells. See Fig. 3 for definition of dissociation constants. 
A
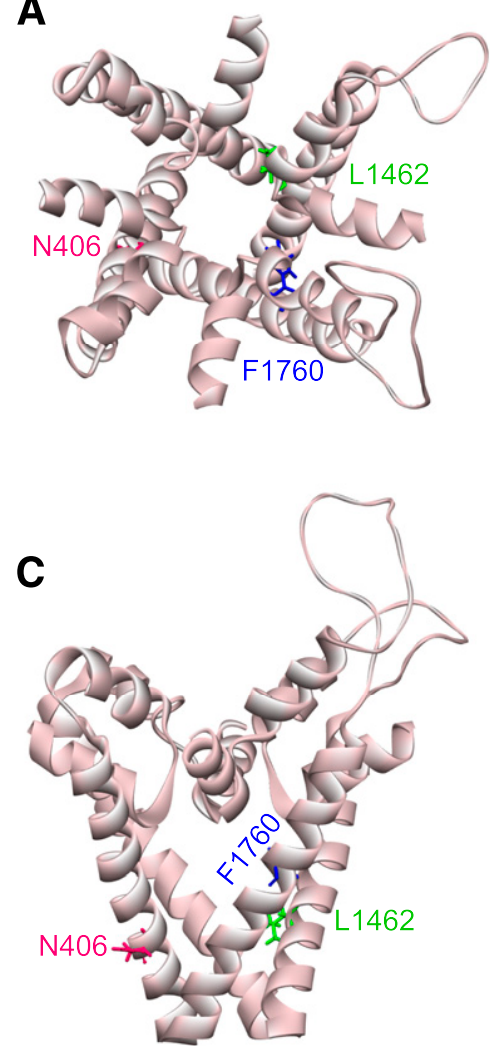

B

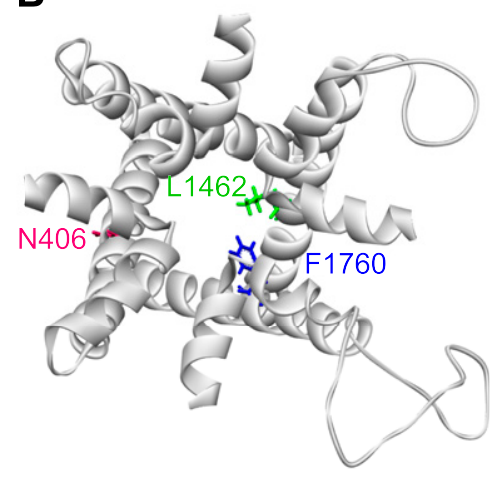

D

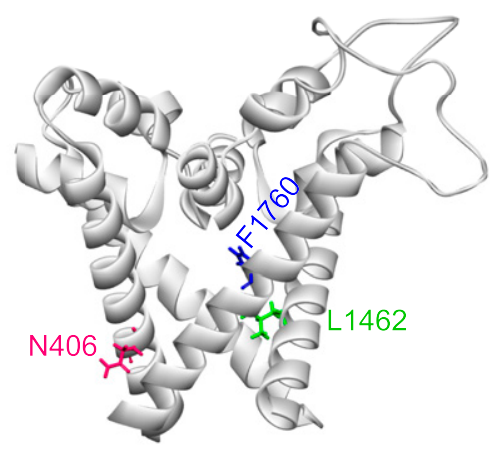

Fig. 6. The pore models of closed and open $\mathrm{Na}_{\mathrm{v}} 1.5$ channels based on the structures of bacterial $\mathrm{Na}^{+}$channels, $\mathrm{Na}_{\mathrm{v}} \mathrm{Ab}$ (for closed channel), and $\mathrm{Na}_{\mathrm{v}} \mathrm{Ms}$ (for open channel). (A and C) Closed $\mathrm{Na}_{\mathrm{v}} 1.5$ channels. (B and D) Open $\mathrm{Na}_{\mathrm{v}} 1.5$ channels. (A and B) Top views of channels. (C and D) Side views of channels. Each pore model was composed of P1 and P2 helices, nonhelix linkers including selectivity filter residues between P1 and P2 helices, and S6 segments. The linkers between P2 helices and S6 helices are also shown, but their location and arrangement are not necessarily based on the homology sequences of $\mathrm{Na}_{\mathrm{v}} \mathrm{Ab}$ and $\mathrm{Na}_{\mathrm{v}} \mathrm{Ms}$. The closed and open channels are colored light pink and silver, respectively; the helices and the linkers are shown as ribbons and rods, respectively. Residues N406 (red) in domain I S6 (DIS6), L1462 (green) in DIIIS6, and F1760 (blue) in DIVS6 are represented as sticks. in a similar way to that in $\mathrm{Na}_{\mathrm{v}} 1.5$. That is, mexiletine was located away from L1280 and F1579 in the closed $\mathrm{Na}_{\mathrm{v}} 1.4$ channel, but mexiletine moved closer to F1760. The drug interacted with F1760 through a $\pi-\pi$ interaction with a distance of $4.30 \AA$ between the aromatic ring centers of the drug and F1760 in the open $\mathrm{Na}_{\mathrm{v}} 1.4$ channel (Fig. 8, C and D).

These results suggest that the interaction between mexiletine and the pore residues depends on the channel isoforms and the states of the channel, and that high-affinity binding of mexiletine in the open states of $\mathrm{Na}_{\mathrm{v}} 1.4$ and $\mathrm{Na}_{\mathrm{v}} 1.5$ is caused by a $\pi-\pi$ interaction with Phe.

Docking Simulations of Mexiletine in the Inner Pore of the Open $\mathrm{Na}_{\mathbf{v}}$ 1.5 Mutant Channels. In the present mutational studies of $\mathrm{Na}_{\mathrm{v}} 1.5, \mathrm{~F} 1760 \mathrm{~A}$ and L1462E decreased the affinities of mexiletine for the open and inactivated states. In contrast, L1462F increased drug affinities for the open and inactivated states. To examine the relative location of mexiletine in these mutant channels, we docked mexiletine inside the inner pore of the open mutant channels. In the open F1760A channel, mexiletine was located far away from A1760, and specific interactions between mexiletine and A1760 were not observed (Fig. 9A), which resulted in decreased affinities of mexiletine for the channel. In the open L1462E channel, mexiletine moved away from $\mathrm{F} 1760$ and interacted with E1462 through a salt bridge or hydrogen bonds (Fig. 9B). A salt bridge was formed between the positively charged tertiary amino group of mexiletine and the negatively charged carboxyl group of E1462 (Fig. 9B), and hydrogen bonds were formed between two amino group hydrogens of mexiletine and the hydroxyl oxygen of E1462 (data not shown).

Despite of the specific interaction of mexiletine with E1462, the observation that L1462E decreased the mexiletine block suggests that the interaction between mexiletine and E1462 was not important in the drug block; rather, less interaction of mexiletine with F1760 appeared to decrease the mexiletine block. On the other hand, in the open L1462F channel, mexiletine was sandwiched between F1760 and a newly substituted residue, Phe at 1462 (Fig. 9C). Mexiletine interacted with F1760 through a T-shaped $\pi-\pi$ interaction with a distance of $3.40 \AA$ and with F1462 through a $\pi-\pi$ interaction with a distance of $4.01 \AA$. The increased affinities of mexiletine caused by $\mathrm{L} 1462 \mathrm{~F}$ appeared to be due to $\pi-\pi$ interactions

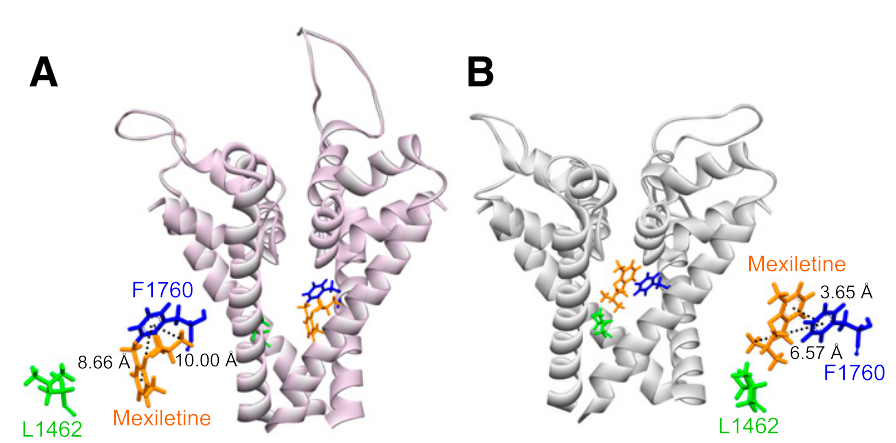

Fig. 7. Docking simulations of mexiletine inside the inner pore of the (A) closed and (B) open $\mathrm{Na}_{\mathrm{v}} 1.5$ channels. Side views of the lowest energy binding orientation of mexiletine (yellow stick) docked inside the inner pore are shown in the closed (A) and open (B) channels. L1462 and F1760 are represented as green and blue sticks, respectively. The left-hand or right-hand inset in each panel is a magnified view showing the relative location of mexiletine to L1462 and F1760, where the distances between the aromatic ring centers of F1760 and mexiletine, and between the aromatic ring center of F1760 and the tertiary amino group of mexiletine are shown. 

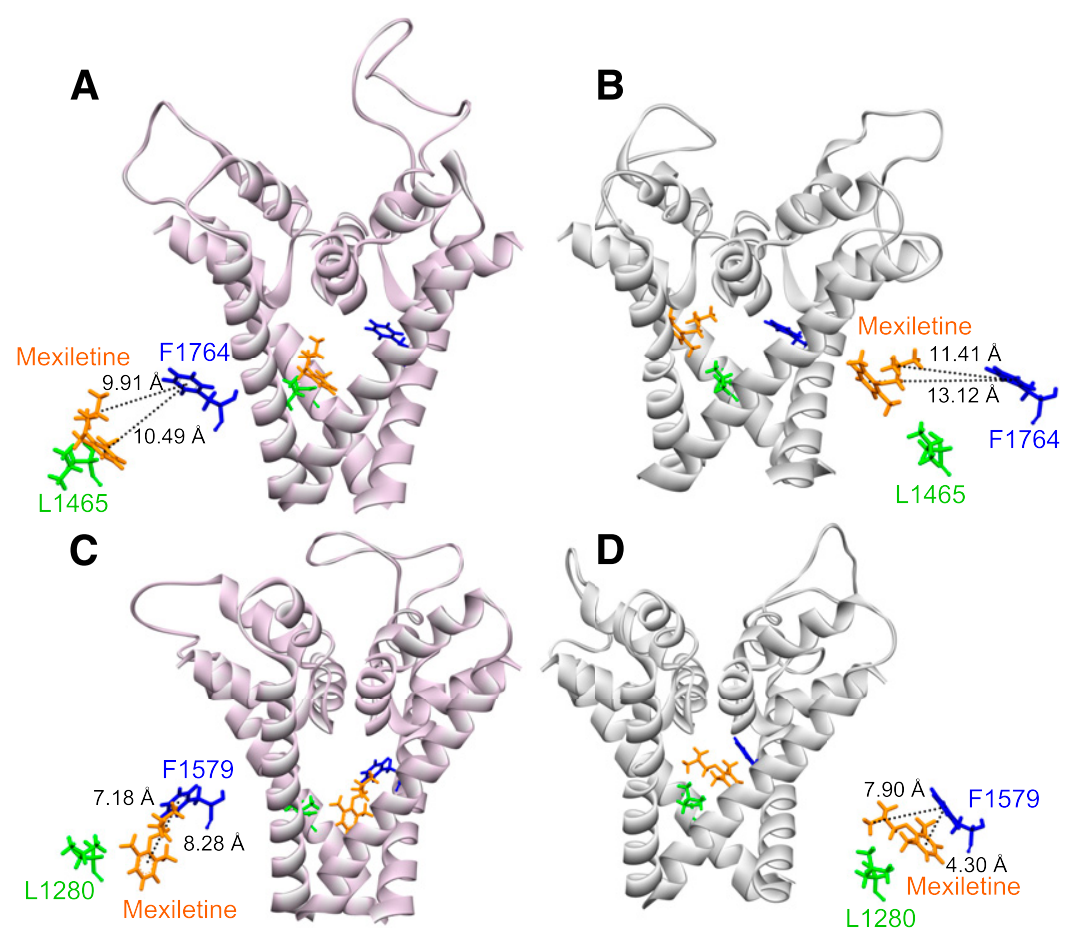

Fig. 8. Docking simulations of mexiletine inside the inner pore of $\mathrm{Na}_{\mathrm{v}} 1.2$ and $\mathrm{Na}_{\mathrm{v}} 1.4$. Side views of the lowest energy binding orientation of mexiletine (yellow stick) docked inside the inner pore are shown in the (A and $\mathrm{C}$ ) closed and $(\mathrm{B}$ and $\mathrm{D})$ open channels for $\mathrm{Na}_{\mathrm{v}} 1.2(\mathrm{~A}$ and $\mathrm{B})$ and $\mathrm{Na}_{\mathrm{v}} 1.4(\mathrm{C}$ and $\mathrm{D})$. Colors and magnified views of the relative location of mexiletine to L1462 and F1760 are the same as described in the legend to Fig. 7.

between the aromatic rings of mexiletine and two phenylalanine residues. These results further support the idea that a $\pi-\pi$ interaction of mexiletine with aromatic residues in the pore is crucial for high-affinity binding of mexiletine to the open channel of $\mathrm{Na}_{\mathrm{v}} 1.5$.

\section{Discussion}

The class Ib antiarrhythmic drug mexiletine is used clinically to reduce or prevent myotonia (Jackson et al., 1994; Hudson et al., 1995) and has neuroprotective effects in models of brain ischemia (Stys and Lesiuk, 1996). To use the drug effectively for heart, muscles, or neurons, the isoformselectivity of the channel block must be taken into account. Therefore, we identified and compared state-dependent affinities of mexiletine for three channel isoforms under the same experimental conditions.

The rested state affinities were not different among these three isoforms. $\mathrm{Na}_{\mathrm{v}} 1.4$ and $\mathrm{Na}_{\mathrm{v}} 1.5$ exhibited similar affinities for the open and inactivated states, which likely contributes to the therapeutic effects of mexiletine on myotonia as well as on cardiac arrhythmia. $\mathrm{Na}_{\mathrm{v}} 1.2$ had a 2 - to 3 -fold lower affinity for these states than did $\mathrm{Na}_{\mathrm{v}} 1.4$ and $\mathrm{Na}_{\mathrm{v}} 1.5$, which was consistent with the previous report showing that affinity of mexiletine for the inactivated channel was 2-fold higher in $\mathrm{Na}_{\mathrm{v}} 1.5$ than in $\mathrm{Na}_{\mathrm{v}} 1.2$ (Weiser et al., 1999).

The rested and inactivated state affinities of $\mathrm{Na}_{\mathrm{v}} 1.4$ obtained here were consistent with the previous study (Wang et al., 2004). The rested state affinity for $\mathrm{Na}_{\mathrm{v}} 1.5$ was also in good agreement with the previous report (Weiser et al., 1999). In contrast, there were big differences in open state affinities between our data and the previous data (Wang et al., 1997, 2004). They directly measured the open state affinity from the mutant channels of $\mathrm{Na}_{\mathrm{v}} 1.4$ or $\mathrm{Na}_{\mathrm{v}} 1.5$ showing the late openings $\left(\mathrm{IC}_{50}\right.$ of about $\left.3 \mu \mathrm{M}\right)$. Because the WT channels of the three isoforms have no or little persistent late currents under normal conditions, we estimated the open state affinity from the total block caused by a train of 30 pulses of 5-millisecond duration applied at 300-millisecond interpulse intervals. Consequently, the open state affinities in $\mathrm{Na}_{\mathrm{v}} 1.4$ and $\mathrm{Na}_{\mathrm{v}} 1.5$ were approximately 30 - to 45 -fold lower than those in the mutant channels (Wang et al., 1997, 2004). More pulses with higher frequency of stimulation may explain the experimental differences between their reports and our experiments. Nonetheless, our estimation of the open state affinity seems unlikely to alter the observation that $\mathrm{Na}_{\mathrm{v}} 1.2$ has lower affinity for the open state than $\mathrm{Na}_{\mathrm{v}} 1.4$ and $\mathrm{Na}_{\mathrm{v}} 1.5$.

In our mutational studies of $\mathrm{Na}_{\mathrm{v}} 1.5, \mathrm{~N} 406 \mathrm{~A}$ increased the affinity of mexiletine for the rested state and decreased affinity for the inactivated state, which was similar to the previous studies of etidocaine and bupivacaine exposed to the equivalent mutations of $\mathrm{Na}_{\mathrm{v}} 1.2$ and $\mathrm{Na}_{\mathrm{v}} 1.4$ (Nau et al., 1999; Yarov-Yarovoy et al., 2002). L1462E and L1462F decreased and increased the affinities of mexiletine for the open and inactivated states, respectively. These findings were similar to the previous studies of bupivacaine using the equivalent mutations of $\mathrm{Na}_{\mathrm{v}} 1.4$ (Nau et al., 2003). In our mutational studies, the biggest impact on mexiletine block was observed in F1760A. F1760A decreased affinities for the rested, open, and inactivated states 2 -fold, 5-fold, and 9-fold, respectively, which resembled the results of the previous study of mexiletine in rat $\mathrm{Na}_{\mathrm{v}} 1.5$ (Weiser et al., 1999).

In our model of $\mathrm{Na}_{\mathrm{v}} 1.5, \mathrm{~L} 1462$ and $\mathrm{F} 1760$ faced the inner pore, and N406 faced away from the pore, irrespective of the channel states. Consistent with our model, the KcsA-based model of the closed $\mathrm{Na}_{\mathrm{v}} 1.5$ channel indicated that Asp does not face the pore (Bruhova et al., 2008). Although N406A changed affinities of mexiletine for the rested and inactivated states, this affinity change seems to be mediated by allosteric influences.

In our docking, mexiletine was located differently depending on the state. In the closed states of $\mathrm{Na}_{\mathrm{v}} 1.4$ and $\mathrm{Na}_{\mathrm{v}} 1.5$, 


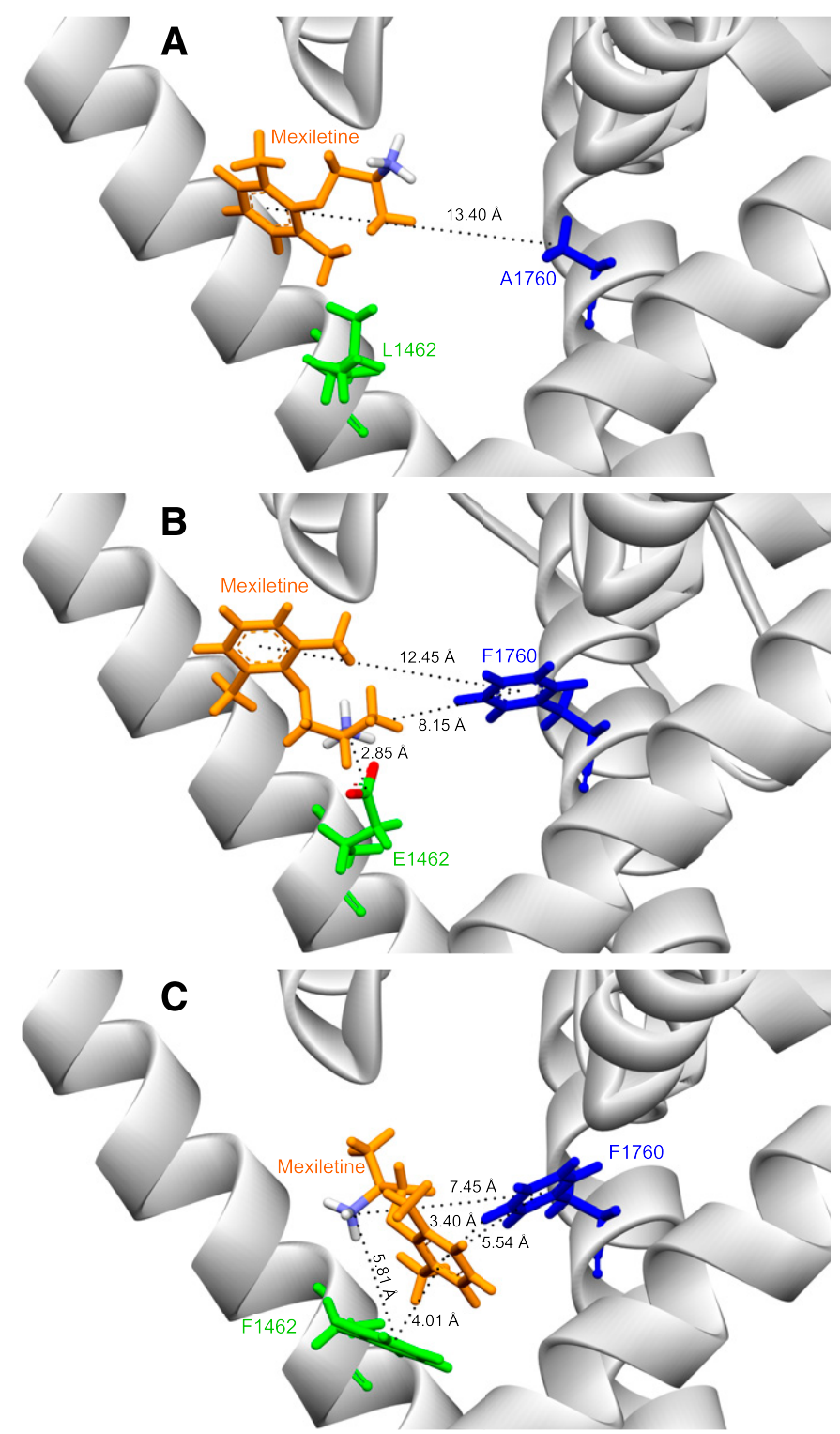

Fig. 9. Detailed view of mexiletine binding in the open $\mathrm{Na}_{\mathrm{v}} 1.5$ mutant channels. Side views of the lowest energy binding orientation of mexiletine (yellow stick) docked inside the inner pore are shown in the open channels of F1760A (A), L1462E (B), and L1462F (C). Domain II S6 is not depicted for clarity in each panel. Residues at 1760 (A1760, F1760) are shown as blue sticks, and residues at 1462 (L1462, E1462, F1462) are shown as green sticks. The distances between F1760 and substituted residues (A1760, E1462, F1462) and the aromatic ring center and the tertiary amino group of mexiletine are depicted to examine whether these pore residues make specific interactions with the drug including $\pi-\pi$ interaction, cation $-\pi$ interaction, salt bridge, and hydrogen bond.

mexiletine was not close to or was located away from Phe. Once $\mathrm{Na}_{\mathrm{v}} 1.4$ and $\mathrm{Na}_{\mathrm{v}} 1.5$ channels opened, mexiletine approached Phe and formed $\pi-\pi$ interactions. Consistent with this, F1760A decreased the affinity of mexiletine more markedly for the open state than for the rested state, suggesting that F1760 is more involved in mexiletine block in the open state than in the closed state. In addition, it is noteworthy that mexiletine is a potent open channel blocker of $\mathrm{Na}_{\mathrm{v}} 1.4$ and $\mathrm{Na}_{\mathrm{v}} 1.5$ (Wang et al., 1997, 2004).

By contrast, in the $\mathrm{Na}_{\mathrm{v}} 1.2$ model mexiletine was located away from Phe even in the open state. The simplest interpretation of these results is that mexiletine has no or little interaction with
Phe in the open state of $\mathrm{Na}_{\mathrm{v}}$ 1.2. To our knowledge, there is no evidence that mexiletine directly interacts with the open state of $\mathrm{Na}_{\mathrm{v}}$ 1.2. In addition, our estimation of the open state affinity of mexiletine showed that $\mathrm{Na}_{\mathrm{v}} 1.2$ has a 2-fold lower affinity for the open state than $\mathrm{Na}_{\mathrm{v}} 1.4$ and $\mathrm{Na}_{\mathrm{v}} 1.5$. These results indicated that $P$ he is not a key residue for mexiletine block in the open state of $\mathrm{Na}_{\mathrm{v}}$ 1.2. Consistent with this, Phe was also less important to mexiletine block in the rested and inactivated states of $\mathrm{Na}_{\mathrm{v}} 1.2$ than to binding of the drug to $\mathrm{Na}_{\mathrm{v}} 1.5$ (Weiser et al., 1999). Instead, another key aromatic residue, Tyr, contributed more importantly to mexiletine block in the inactivated state of $\mathrm{Na}_{\mathrm{v}} 1.2$.

The previous studies using unnatural fluorinated phenylalanine derivatives demonstrated that $\mathrm{Na}_{\mathrm{v}} 1.4$ and $\mathrm{Na}_{\mathrm{v}} 1.5$ channels form cation $-\pi$ interactions with lidocaine and mexiletine at Phe and produce use-dependent block (Ahern et al., 2008; Pless et al., 2011). A cation- $\pi$ interaction likely occurs in the inactivated state because class Ib antiarrhythmic drugs including lidocaine and mexiletine, having higher affinities for the inactivated state, produce use-dependent block through a cation $-\pi$ interaction, but class Ia and Ic drugs including quinidine and flecainide prefer the open channel and rely less on this interaction (Pless et al., 2011). Because mexiletine seems to change its position and orientation depending on the channel state, it is possible that mexiletine binds to Phe through a $\pi-\pi$ interaction in the open state and through a cation- $\pi$ interaction in the inactivated state. Structural models of the inactivated state are not yet available to confirm this hypothesis because prokaryotic $\mathrm{Na}^{+}$channels have no fast inactivation (Pavlov et al., 2005) and the electrophysiological states of electric eel $\mathrm{Na}^{+}$channels with fast inactivation (of which structures were recently reported) are yet to be defined (Yan et al., 2017).

Our models agree with the following experimental data. 1) Mutations of L1462 and F1760 affect mexiletine block, and L1462 and F1760 face the pore in the model. 2) $\mathrm{Na}_{\mathrm{v}} 1.4$ and $\mathrm{Na}_{\mathrm{v}} 1.5$ have similar affinities for the closed and open states, and the relative locations of mexiletine are similar in the models of closed and open states of $\mathrm{Na}_{\mathrm{v}} 1.4$ and $\mathrm{Na}_{\mathrm{v}} 1.5$. 3) $\mathrm{Na}_{\mathrm{v}} 1.2$ has lower affinity for the open state than $\mathrm{Na}_{\mathrm{v}} 1.4$ and $\mathrm{Na}_{\mathrm{v}}$ 1.5, and the relative location of mexiletine in the model of open $\mathrm{Na}_{\mathrm{v}} 1.2$ is different from those of open $\mathrm{Na}_{\mathrm{v}} 1.4$ and $\mathrm{Na}_{\mathrm{v}}$ 1.5. 4) Decrease in affinity mediated by F1760A is more marked in the open state than in the closed state, and mexiletine interacts with F1760 through a $\pi-\pi$ interaction in the model of open $\mathrm{Na}_{\mathrm{v}} 1.5$ and is not close to F1760 in the model of closed $\mathrm{Na}_{\mathrm{v}}$ 1.5. 5) F1760A decreases affinity for the open state 5 -fold $(-1.0 \mathrm{kcal} / \mathrm{mol})$, and mexiletine is located far away from A1760 in the model of the open channel containing F1760A.

In several previous models, local anesthetics adopted a horizontal orientation with respect to the ion permeation pathway in the closed channel and a vertical orientation in the open channel (Lipkind and Fozzard, 2005; Tikhonov et al., 2006; Tikhonov and Zhorov, 2007, 2012; Bruhova et al., 2008). On the other hand, several local anesthetics adopt horizontal, vertical, and intermediate (angular) orientations in the closed channel (Bruhova et al., 2008), and horizontal and two distinct vertical orientations in the open channel (Tikhonov and Zhorov, 2017). In our docking, mexiletine appeared not to adopt either horizontal or vertical orientations in any state. Differences in ligand orientations among the models might be, 
in part, because of different channel templates used, different channel states, and different channel isoforms.

In our model, mexiletine occurred closer to the extracellular space in the open channel regardless of the channel isoform. This may facilitate the electrostatic mechanism of block (Lipkind and Fozzard, 2005; Tikhonov et al., 2006; McNulty et al., 2007) and explain a greater block in the open channel. Specific binding of the aromatic ring of mexiletine to Phe likely helps locate the ammonium group upward in $\mathrm{Na}_{\mathrm{v}} 1.4$ and $\mathrm{Na}_{\mathrm{v}}$ 1.5. In addition, our docking and experimental results suggest that the amino acid residues lining the pore, which are common to $\mathrm{Na}_{\mathrm{v}} 1.4$ and $\mathrm{Na}_{\mathrm{v}} 1.5$ but not common to $\mathrm{Na}_{\mathrm{v}} 1.2$ (Fig. 1 ), may help mexiletine form a $\pi-\pi$ interaction with Phe in the open states. Consequently, mexiletine may work better in $\mathrm{Na}_{\mathrm{v}} 1.4$ or $\mathrm{Na}_{\mathrm{v}} 1.5$ than $\mathrm{Na}_{\mathrm{v}}$ 1.2. Further experimental studies are needed to test this hypothesis.

In conclusion, $\mathrm{Na}_{\mathrm{v}} 1.4$ and $\mathrm{Na}_{\mathrm{v}} 1.5$ had similar affinities and interactions for mexiletine. This may explain the therapeutic effects of mexiletine on myotonia as well as on cardiac arrhythmia. Visualization of isoform differences in statedependent block may contribute to rational design of isoformselective and safer drugs.

\section{Acknowledgments}

We are indebted to Dr. H. A. Fozzard for his support of this work and to Dr. S. C. Dudley for reading and commenting on the manuscript. Dr. N. Makita generously provided the $\mathrm{Na}_{\mathrm{v}} 1.5$ clone. The technical assistance of $\mathrm{N}$. Ishimaru is also appreciated.

\section{Authorship Contributions}

Participated in research design: Nakagawa, Munakata, Sunami.

Conducted experiments: Nakagawa, Munakata, Sunami.

Performed data analysis: Nakagawa, Munakata, Sunami.

Wrote or contributed to the writing of the manuscript: Nakagawa, Munakata, Sunami.

\section{References}

Ahern CA, Eastwood AL, Dougherty DA, and Horn R (2008) Electrostatic contributions of aromatic residues in the local anesthetic receptor of voltage-gated sodium channels. Circ Res 102:86-94.

Bagnéris C, Naylor CE, McCusker EC, and Wallace BA (2015) Structural model of the open-closed-inactivated cycle of prokaryotic voltage-gated sodium channels. $J$ Gen Physiol 145:5-16.

Bruhova I, Tikhonov DB, and Zhorov BS (2008) Access and binding of local anesthetics in the closed sodium channel. Mol Pharmacol 74:1033-1045.

Camerino DC, Tricarico D, and Desaphy JF (2007) Ion channel pharmacology. Neurotherapeutics 4:184-198.

Carmeliet E and Mubagwa K (1998) Antiarrhythmic drugs and cardiac ion channels: mechanisms of action. Prog Biophys Mol Biol 70:1-72.

Chabal C, Jacobson L, Mariano A, Chaney E, and Britell CW (1992) The use of oral mexiletine for the treatment of pain after peripheral nerve injury. Anesthesiology 76:513-517.

Dassault Systemes Biovia (2016) Discovery Studio Visualizer, Discovery Studio Modeling Environment, Dassault Systèmes, San Diego, CA.

Fozzard HA and Hanck DA (1996) Structure and function of voltage-dependent sodium channels: comparison of brain II and cardiac isoforms. Physiol Rev 76: 887-926.

Hudson AJ, Ebers GC, and Bulman DE (1995) The skeletal muscle sodium and chloride channel diseases. Brain 118:547-563.

Jackson CE, Barohn RJ, and Ptacek LJ (1994) Paramyotonia congenita: abnormal short exercise test, and improvement after mexiletine therapy. Muscle Nerve 17: $763-768$.

Kawagoe H, Yamaoka K, Kinoshita E, Fujimoto Y, Maejima H, Yuki T, and Seyama I (2002) Molecular basis for exaggerated sensitivity to mexiletine in the cardiac isoform of the fast Na channel. FEBS Lett 513:235-241.

Lipkind GM and Fozzard HA (2005) Molecular modeling of local anesthetic drug binding by voltage-gated sodium channels. Mol Pharmacol 68:1611-1622.

McCusker EC, Bagnéris C, Naylor CE, Cole AR, D’Avanzo N, Nichols CG, and Wallace BA (2012) Structure of a bacterial voltage-gated sodium channel pore reveals mechanisms of opening and closing. Nat Commun 3:1102.
McNulty MM, Edgerton GB, Shah RD, Hanck DA, Fozzard HA, and Lipkind GM (2007) Charge at the lidocaine binding site residue Phe-1759 affects permeation in human cardiac voltage-gated sodium channels. J Physiol 581:741-755.

Morris GM, Huey R, Lindstrom W, Sanner MF, Belew RK, Goodsell DS, and Olson AJ (2009) AutoDock4 and AutoDockTools4: automated docking with selective receptor flexibility. J Comput Chem 30:2785-2791.

Nau C, Wang SY, Strichartz GR, and Wang GK (1999) Point mutations at N434 in D1-S6 of mu1 $\left.\mathrm{Na}^{+}\right)$channels modulate binding affinity and stereoselectivity of local anesthetic enantiomers. Mol Pharmacol 56:404-413.

Nau C, Wang SY, and Wang GK (2003) Point mutations at L1280 in Nav1.4 channel D3-S6 modulate binding affinity and stereoselectivity of bupivacaine enantiomers. Mol Pharmacol 63:1398-1406.

Ono M, Sunami A, Sawanobori T, and Hiraoka M (1994) External pH modifies sodium channel block by mexiletine in guinea pig ventricular myocytes. Cardiovasc Res 28:973-979.

Pavlov E, Bladen C, Winkfein R, Diao C, Dhaliwal P, and French RJ (2005) The pore, not cytoplasmic domains, underlies inactivation in a prokaryotic sodium channel. Biophys $J$ 89:232-242.

Payandeh J, Scheuer T, Zheng N, and Catterall WA (2011) The crystal structure of a voltage-gated sodium channel. Nature 475:353-358.

Pless SA, Galpin JD, Frankel A, and Ahern CA (2011) Molecular basis for class Ib anti-arrhythmic inhibition of cardiac sodium channels. Nat Commun 2:351.

Ragsdale DS, McPhee JC, Scheuer T, and Catterall WA (1994) Molecular determinants of state-dependent block of $\mathrm{Na}^{+}$channels by local anesthetics. Science $\mathbf{2 6 5}$ : 1724-1728.

Ragsdale DS, McPhee JC, Scheuer T, and Catterall WA (1996) Common molecular determinants of local anesthetic, antiarrhythmic, and anticonvulsant block of voltage-gated $\mathrm{Na}^{+}$channels. Proc Natl Acad Sci USA 93:9270-9275.

Sali A and Blundell TL (1993) Comparative protein modelling by satisfaction of spatial restraints. $J$ Mol Biol 234:779-815

Sasaki K, Makita N, Sunami A, Sakurada H, Shirai N, Yokoi H, Kimura A, Tohse N, Hiraoka M, and Kitabatake A (2004) Unexpected mexiletine responses of a mutant cardiac $\mathrm{Na}^{+}$channel implicate the selectivity filter as a structural determinant of antiarrhythmic drug access. Mol Pharmacol 66:330-336.

Stys PK and Lesiuk H (1996) Correlation between electrophysiological effects of mexiletine and ischemic protection in central nervous system white matter. $\mathrm{Neu}$ roscience $\mathbf{7 1 : 2 7 - 3 6}$

Sula A, Booker J, Ng LC, Naylor CE, DeCaen PG, and Wallace BA (2017) The complete structure of an activated open sodium channel. Nat Commun 8:14205.

Sunami A, Tracey A, Glaaser IW, Lipkind GM, Hanck DA, and Fozzard HA (2004) Accessibility of mid-segment domain IV S6 residues of the voltage-gated $\mathrm{Na}^{+}$ channel to methanethiosulfonate reagents. J Physiol 561:403-413.

Tikhonov DB, Bruhova I, and Zhorov BS (2006) Atomic determinants of statedependent block of sodium channels by charged local anesthetics and benzocaine. FEBS Lett 580:6027-6032.

Tikhonov DB and Zhorov BS (2007) Sodium channels: ionic model of slow inactivation and state-dependent drug binding. Biophys $J$ 93:1557-1570.

Tikhonov DB and Zhorov BS (2012) Architecture and pore block of eukaryotic voltage-gated sodium channels in view of NavAb bacterial sodium channel structure. Mol Pharmacol 82:97-104.

Tikhonov DB and Zhorov BS (2017) Mechanism of sodium channel block by local anesthetics, antiarrhythmics, and anticonvulsants. J Gen Physiol 149:465-481.

Wang DW, Yazawa K, Makita N, George AL Jr, and Bennett PB (1997) Pharmacological targeting of long QT mutant sodium channels. J Clin Invest 99:1714-1720. Wang GK, Quan C, and Wang SY (1998) Local anesthetic block of batrachotoxinresistant muscle $\mathrm{Na}^{+}$channels. Mol Pharmacol 54:389-396.

Wang GK, Russell C, and Wang SY (2004) Mexiletine block of wild-type and inactivation-deficient human skeletal muscle hNav1.4 $\mathrm{Na}^{+}$channels. $J$ Physiol 554:621-633.

Wang SY, Nau C, and Wang GK (2000) Residues in Na( ${ }^{+}$) channel D3-S6 segment modulate both batrachotoxin and local anesthetic affinities. Biophys $J$ 79: 1379-1387.

Wang Y, Mi J, Lu K, Lu Y, and Wang K (2015) Comparison of gating properties and use-dependent block of Nav1.5 and Nav1.7 channels by anti-arrhythmics mexiletine and lidocaine. PLoS One 10:e0128653.

Weiser T, Qu Y, Catterall WA, and Scheuer T (1999) Differential interaction of R-mexiletine with the local anesthetic receptor site on brain and heart sodium channel alpha-subunits. Mol Pharmacol 56:1238-1244.

Yan Z, Zhou Q, Wang L, Wu J, Zhao Y, Huang G, Peng W, Shen H, Lei J, and Yan N (2017) Structure of the $\mathrm{Na}_{\mathrm{v}} 1.4-\beta 1$ complex from electric eel. Cell 170:470-482.e11.

Yarov-Yarovoy V, Brown J, Sharp EM, Clare JJ, Scheuer T, and Catterall WA (2001) Molecular determinants of voltage-dependent gating and binding of pore-blocking drugs in transmembrane segment IIIS6 of the $\left.\mathrm{Na}^{+}\right)$channel alpha subunit. $\mathrm{J} \mathrm{Biol}$ Chem 276:20-27.

Yarov-Yarovoy V, McPhee JC, Idsvoog D, Pate C, Scheuer T, and Catterall WA (2002) Role of amino acid residues in transmembrane segments IS6 and IIS6 of the $\mathrm{Na}^{+}$ channel alpha subunit in voltage-dependent gating and drug block. J Biol Chem 277:35393-35401.

Address correspondence to: Dr. Akihiko Sunami, Department of Pharmaceutical Sciences, International University of Health and Welfare, 2600-1 Kitakanemaru, Ohtawara, Tochigi 324-8501, Japan. E-mail: asunami@iuhw. ac.jp 